\title{
Predictors of High-grade Vesicoureteral Reflux in Children with Febrile Urinary Tract Infections
}

\author{
Eom Ji Choi, M.D. \\ Min Ju Lee, M.D. \\ Sin-Ae Park, M.D. \\ Oh-Kyung Lee, M.D. \\ Department of Pediatrics, Presbyterian \\ Medical Center, Jeonju, Korea
}

\footnotetext{
*This study was approved by the Presbyterian Medical Center Institutional Review Board (IRB; 2017-04-011)

Corresponding author: Oh-Kyung Lee, M.D. Department of Pediatrics, Presbyterian Medical Center, 365, Seowon-ro, Wansangu, Jeonju-si, Jeollabuk-do 54987, Korea Tel: +82-63-230-1390

Fax: +82-63-230-1396

E-mail: okleepmc@naver.com
}

Received: 14 August 2017

Revised: 13 September 2017

Accepted: 27 September 2017
Purpose: This study aimed to investigate clinical and radiological factors that may predict high-grade vesicoureteral reflux (VUR) in patients with febrile urinary tract infection (UTI).

Methods: We retrospectively analyzed medical records of 446 patients diagnosed with febrile UTI from March 2008 to February 2017. All patients underwent renalbladder ultrasonography (RBUS), 99mTc dimercaptosuccinic acid (DMSA) renal scan, and voiding cystourethrography (VCUG), and were divided in to 3 groups: a high-grade VUR group $(n=53)$, a low-grade VUR group $(n=28)$, and a group without VUR $(n=365)$.

Results: The recurrence and non-Escherichia coli infection rates in febrile UTI were significantly higher in the high-grade VUR group than in the other two groups $(P<0.05)$. RBUS showed that hydronephrosis and ureter dilatation were more frequent in the high-grade VUR group than in the other groups $(P<0.05)$. In the high-grade VUR group, a renal cortical defect was more likely to appear as multiple defects, and the difference in bilateral renal scan uptake between both kidneys was larger than in the other two groups $(P<0.001)$.

Conclusion: Recurrent UTI, non-E. coli UTI, abnormal findings on RBUS such as hydronephrosis and ureter dilatation, and abnormal findings in the DMSA renal scan such as multiple renal cortical defects and greater uptake difference were associated with high-grade VUR. VCUG should be selectively performed when RBUS and/or DMSA renal scan reveal significant abnormalities.

Key words: Vesicoureteral reflux, Urinary tract infection, Children

\section{Introduction}

Urinary tract infection (UTI) is the most common bacterial disease in children, occurring in $1 \%$ of boys and $1-3 \%$ of girls ${ }^{11}$. UTI is often associated with primary vesicoureteral reflux (VUR), and primary VUR is diagnosed in about

This is an open-access article distributed under the terms of the Creative Commons Attribution Non-Commercial License (http:// creativecommons.org/licenses/by-nc/4.0/) which permits unrestricted non-commercial use, distribution, and reproduction in any medium, provided the original work is properly cited. $(\mathrm{VCUG})^{2,3)}$.

However, VCUG is an expensive, invasive procedure that exposes the patient to radiation, and recent studies have shown that prescribing prophylactic antibiotic medication is ineffective at preventing recurrence of UTIs in pediatric patients with $\mathrm{VUR}^{4-6}$. Since low-grade VURs (grade I, II and III) often disappears naturally as the patient grows, several guidelines are no longer recommending routine VCUG for the first occurrence of $\mathrm{UTI}^{4,7-10)}$. 
Whereas high-grade VURs (grade IV and V) are less likely to resolve spontaneously, and cause complications such as renal scarring, hypertension, and end-stage renal disease due to recurrent $\mathrm{UTI}^{8,11-14)}$. Therefore, confirming high-grade VURs may help to improve prognoses for pediatric patients with VURs.

For these reasons, several studies have been performed exploring predictive factors for VUR. Various factors have been suggested: clinical factors, such as recurrence and severity of fever, laboratory findings, such as higher CRP level, and radiological findings, such as abnormal renal-bladder ultrasonography (RBUS) and 99mTc Dimercaptosuccinic acid (DMSA) renal scan. However, there are few studies regarding the rationale on selectively performing VCUG for detection of VUR ${ }^{15-20)}$.

The present study aimed to analyze the relationship between severity of VUR and clinical and radiological findings in children with febrile UTI. From our results, we discuss on the necessity of selective modality of VCUG only when high-grade VUR is suspected.

\section{Materials and methods}

Among children admitted to the department of Pediatrics at Presbyterian Medical Center in Jeonju between March 2008 and February 2017, we retrospectively analyzed medical records of 446 patients with febrile UTI. All patients were under 15-years-old and underwent RBUS, DMSA renal scan, and VCUG. Febrile UTI was defined as a fever of at least $38^{\circ} \mathrm{C}$ (measured by a tympanic thermometer) with the presence of at least $5 \times 10^{4} \mathrm{CFU} / \mathrm{ml}$ of a single bacterial strain in urine collected by suprapubic aspiration or a catheter, or the presence of at least $10^{5} \mathrm{CFU} / \mathrm{mL}$ of a single bacterial strain in urine collected with a sterile urine collection bag. RBUS was performed on patients within 3 days after hospitalization, and DMSA renal scan was performed within 7 days. VCUG was performed after urine culture was confirmed to be negative during hospitalization.

According to the results of VCUG performed in all patients (446), there were 81 patients (18.1\%) had VUR, and among them 28 patients had low-grade (grade I, II, and III) VUR and 53 patients had high-grade VUR (grade IV and V) based on the Classification system of the International
Reflux Study Committee. In cases of bilateral refluxes, the more severe side was graded.

Age, sex, total fever duration, recurrence, white blood cell (WBC) count, and C-reactive protein (CRP), and radiological findings in RBUS and DMSA renal scan were compared across the three groups: the high-grade VUR group, the low-grade VUR group, and the group without VUR. Abnormal findings in RBUS were categorized as bladder wall thickening, hydronephrosis, change in cortical echogenicity, change in kidney size, and ureteral dilation based on the interpretation of a radiological specialist. Hydronephrosis was diagnosed based on the Society of Fetal Urology grading system. The DMSA scan results were categorized based on the interpretation of a specialist in Nuclear Medicine, according to the presence or absence and the extent of renal cortical defects. A single local defect on a single nephron was defined as a focal renal cortical defect, while two or more defects on a single nephron or defects on both renal cortices was defined as a multiple renal cortical defect. The uptake (\%) in each kidney was also measured from the DMSA scan, and the uptake difference (\%) between the two kidneys was calculated. In order to monitor the recurrence of febrile UTI, the medical records of the patients were reviewed for at least 6 months from the time of discharge.

\section{Statistical analysis}

SPSS version 22.0 (IBM SPSS Statistics) was used for statistical analysis. Frequency analysis, descriptive statistics, Student's t-test, chi-square test, and one-way ANOVA test were performed. Statistical significance was defined as a $P$-value of less than 0.05 .

\section{Results}

\section{Demographic and clinical findings}

The mean age of the 3 groups were $11.9 \pm 19.8$ months, $11.1 \pm 15.2$ months, and $8.3 \pm 15.4$ months, respectively, which was lower in the group without VUR, but there was no difference among the three groups. There were no differences in male to female ratio among the groups.

The mean total fever duration were $3.1 \pm 2.0$ days, $2.8 \pm 1.6$ days, $2.9 \pm 1.9$ days, respectively, with no statistical diffe- 
rences.

The recurrence of febrile UTI was higher in the group with high-grade VUR (41.5\%, 22 out of 53) compared to the groups with low-grade VUR or without VUR $(17.9 \%$ and $14.0 \%, P<0.001$ ) (Table 1 ).

\section{Laboratory comparison among 3 the groups}

The mean WBC count were 17,700 $\pm 6,700 / \mu \mathrm{L}, 18,000 \pm$ $7,900 / \mu \mathrm{L}$ and $16,000 \pm 6,500 / \mu \mathrm{L}$, respectively. The mean CRP was $6.4 \pm 5.7 \mathrm{mg} / \mathrm{dL}, 6.2 \pm 4.8 \mathrm{mg} / \mathrm{dL}, 5.6 \pm 5.0 \mathrm{mg} / \mathrm{dL}$, respectively, and there were no differences in WBC and CRP levels in the 3 groups (Table 1).

In urine culture tests, positive rates of Escherichia coli (E. coli) growth were $71.7 \%, 89.3 \%$, and $91.0 \%$, respectively. Other bacteria included Klebsiella pneumoniae, Enterococcus Faecalis, Citrobacter freundii, Klebsiella oxytoca, Morganella morganii, Proteus mirabilis, Enterobacter cloacae, Enterococcus faecium, Staphylococcus aureus, Streptococcus agalactiae, Pseudomonas aeruginosa, and Enterobacter aerogenes. The proportion of positive patients for bacteria other than $E$. coli was $28.3 \%(15 / 53)$ in the group with high-grade VUR, 10.7\% (3/28) in the group with lowgrade VUR and 9.0\% (33/365) in the group without VUR, with a statistical significance $(P=0.001)$ (Table 1$)$.

\section{Radiological findings comparison among the 3 groups}

The proportion of total abnormal findings in RBUS was $69.8 \%, 50.0 \%$, and $55.1 \%$ in the 3 groups with no differences.

However, the proportion with hydronephrosis was 47.2 $\%, 28.6 \%$ and $25.4 \%$, respectively, with a statistical difference $(P=0.004)$. Compared with the other two groups, there was a trend of higher proportion of $\geq$ grade 2 of hydronephrosis in the group with high-grade VUR.

Among the other US findings, the proportion of ureter dilation was significantly higher in the group with highgrade VUR $(P=0.002)$. But bladder thickening was not a statistically significant difference among the groups. Also, the changes in kidney echogenicity and the changes in kidney size were not different among the groups (Table 2).

With respect to DMSA renal scan findings, the positive rates of DMSA renal scans were $86.8 \%, 85.7 \%$ and $65.2 \%$, respectively, showing that renal cortical defects were significantly more common in patients with VUR $(P=0.001)$. Of these, the proportion of multiple renal cortical defects was significantly higher in the group with high-grade VUR

Table 1. Comparison of Clinical Characteristics and Laboratory Characteristics of Group with Vesicoureteral Reflux and Group without Vesicoureteral Reflux

\begin{tabular}{|c|c|c|c|c|}
\hline Characteristics & High grade VUR $(n=53)$ & Low grade VUR $(n=28)$ & No VUR $(n=365)$ & $P$-value \\
\hline Age (month) & $11.9 \pm 19.8$ & $11.1 \pm 15.2$ & $8.2 \pm 15.5$ & 0.219 \\
\hline $\operatorname{Sex}(M: F)$ & $66.0: 34.0$ & $57.1: 42.9$ & $70.7: 29.3$ & 0.281 \\
\hline Total fever duration (days) & $3.1 \pm 2.0$ & $2.8 \pm 1.6$ & $2.9 \pm 1.9$ & 0.761 \\
\hline Recurrent infection (\%) & $41.5 \%$ & $17.9 \%$ & $14.0 \%$ & 0.000 \\
\hline WBC count $(/ \mu \mathrm{L})$ & $17,700 \pm 6,700$ & $18,000 \pm 7,900$ & $16,200 \pm 6,500$ & 0.148 \\
\hline $\mathrm{CRP}(\mathrm{mg} / \mathrm{dL})$ & $6.4 \pm 5.7$ & $6.2 \pm 4.8$ & $5.6 \pm 5.0$ & 0.469 \\
\hline Non-E. coli UTI (\%) & $28.3 \%$ & $10.7 \%$ & $9.0 \%$ & 0.001 \\
\hline
\end{tabular}

Abbreviations: VUR, Vesicoureteral reflux; UTI, Urinary tract infection; WBC, White blood cell; CRP, C-reactive protein.

Table 2. Comparison of Renal-Bladder Ultrasonography Findings of Group with Vesicoureteral Reflux and Group without Vesicoureteral Reflux

\begin{tabular}{lcccc}
\hline RBUS findings & High grade VUR $(\mathrm{n}=53)$ & Low grade VUR $(\mathrm{n}=28)$ & No VUR $(\mathrm{n}=365)$ & $P$-value \\
\hline Bladder thickening, $\mathrm{n}(\%)$ & $10(18.9 \%)$ & $3(10.7 \%)$ & $79(21.6 \%)$ & 0.401 \\
Hydronephrosis, $\mathrm{n}(\%)$ & $25(47.2 \%)$ & $8(28.6 \%)$ & $92(25.2 \%)$ & 0.004 \\
Grade 1 & $21(39.6 \%)$ & $7(25.0 \%)$ & $80(21.9 \%)$ & 0.016 \\
Grade $\geq 2$ & $4(7.5 \%)$ & $1(3.6 \%)$ & $12(3.3 \%)$ & 0.264 \\
Ureter dilatation, $\mathrm{n}(\%)$ & $6(11.3 \%)$ & $0(0 \%)$ & $5(1.4 \%)$ & 0.002 \\
Change in kidney size, $\mathrm{n}(\%)$ & $5(9.4 \%)$ & $5(17.9 \%)$ & $30(8.2 \%)$ & 0.226 \\
Change in kidney echogenicity, $\mathrm{n}(\%)$ & $15(28.3 \%)$ & $7(25.0 \%)$ & $70(19.2 \%)$ & 0.259 \\
\hline
\end{tabular}

Abbreviations: RBUS, Renal-bladder ultrasonography; VUR, Vesicoureteral reflux. 
as shown $58.5 \%, 14.3 \%$, and $25.2 \%$, respectively $(P<0.001)$.

Also, the uptake difference (\%) between the two kidneys in DMSA renal scan findings was greater in the group with high-grade VUR as shown $16.3 \pm 16.3 \%, 9.6 \pm 7.1 \%$, and $7.6 \pm$ $6.4 \%$, respectively $(P<0.001)$ (Table 3$)$.

\section{Discussion}

In the present study, we found that patients with highgrade VUR were more likely to experience recurrence of febrile UTI with higher rate of infection with bacteria other than E. coli compared to those with low-grade VUR or those without VUR. Moreover, patients with high-grade VUR had more hydronephrosis and ureter dilation on RBUS, and more multiple pattern of renal cortical defects on DMSA, and showed a larger difference in renal scan uptake between the two kidneys.

In several previous studies, VUR has been believed as a cause of recurrent UTI and renal scarring ${ }^{8,14,21)}$. For this reason, the AAP guidelines state that VCUG should be performed after the second occurrence of UTI in order to identify patients with VUR, and the NICE guidelines recommend performing VCUG in cases of recurrent UTI in patients under 6-months-old ${ }^{4,9)}$. Jang et al. reported that grade 3 or higher grade VUR and bilateral VUR significantly increased the risk of recurrent $\mathrm{UTI}^{22}$. The results of the present study also showed a higher frequency of recurrent UTI in high-grade VUR patients, suggesting that VCUG should be considered in recurrent UTI patients.

E. coli is known to be the most common species of bacteria causing UTI, accounting for approximately $80 \%$ of cases $^{3)}$. As shown in this study, other bacteria known to cause UTI include Klebsiella, Enterobacter, Proteus, Citrobacter. Pseudomonas, Staphylococcus aureus, and Streptococcus $^{3,20,21,23)}$. Several previous studies have reported that patients infected with non-E. coli UTI have relatively milder clinical and laboratory findings such as low grade fever, lower WBC and ESR compared to those infected with $E$. $c o l i$. It has been reported that non-E. coli pathogens are more often isolated in patients with urinary tract anomalies, such as VUR, and they are associated with a higher incidence of renal scarring after pyelonephritis ${ }^{24-26)}$. Pauchard et al. reported that patients infected with non- $E$. coli bacteria had a higher probability for high-grade VUR in infants younger than 3 months ${ }^{27)}$. In addition, the NICE guidelines published in 2007 stated that VCUG should be considered for non-E. coli $\mathrm{UTI}^{9)}$. In present study, we also found that the patients with high-grade VUR showed a higher proportion of non-E. coli UTI.

RBUS is one of the most commonly used imaging methods to identify inflammatory changes in the kidneys and bladder, as well as congenital deformities, such as VUR, in children patients with UTI. Although there have been many studies to evaluate whether RBUS can be used to predict the presence or absence of VUR, these studies showed limitations of RBUS in this issue ${ }^{16,17,30)}$. However, other investigators have reported that severe abnormal RBUS findings, such as high-grade hydronephrosis, change in cortical echogenicity, or ureter dilatation may helpful to perform $\mathrm{VCUG}^{18,19)}$. In the present study, total hydronephrosis were associated with high-grade VUR. However, hydronephrosis of grade 2 or higher was not associated with high-grade VUR. This may be due to the fact that the number of patients with hydronephrosis of grade 2 or higher were very small compared with the number of total patients. We found that the ureter dilatation was associated with highgrade VUR. Therefore, in accordance with the AAP and other existing guidelines, we believe that it is important to perform VCUG to verify the presence or absence of VUR in patients with abnormal findings, such as hydronephrosis or ureter dilatation, on RBUS ${ }^{4)}$.

DMSA renal scan is a standard method to identify renal parenchymal injury and renal scarring. There has been

Table 3. Comparison of 99mTc Dimercaptosuccinic Acid Renal Scan Findings of Group with Vesicoureteral Reflux and Group without Vesicoureteral Reflux

\begin{tabular}{lcccc}
\hline DMSA findings & High grade VUR $(\mathrm{n}=53)$ & Low grade VUR $(\mathrm{n}=28)$ & No VUR $(\mathrm{n}=365)$ & $P$-value \\
\hline Positive, $\mathrm{n}(\%)$ & $46(86.8 \%)$ & $24(85.7 \%)$ & $238(65.2 \%)$ & 0.001 \\
Multiple renal cortex defect, $\mathrm{n}(\%)$ & $31(58.5 \%)$ & $4(14.3 \%)$ & $92(25.2 \%)$ & 0.000 \\
Uptake difference (\%) & $16.3 \pm 16.3$ & $9.6 \pm 7.1$ & $7.6 \pm 6.4$ & 0.000 \\
\hline
\end{tabular}

Abbreviations: DMSA, 99mTc Dimercaptosuccinic acid; VUR, Vesicoureteral reflux. 
many studies regarding the predicting role of DMSA scan to detect VUR ${ }^{31-35)}$. Fouzas et al. claimed that DMSA renal scan had an overall limited ability to identify VUR and could not replace VCUG in children with a first febrile UTI. However, Sheu et al. reported that DMSA renal scan was useful to predict the presence of higher VUR in children aged two years or younger ${ }^{32,33)}$. Other investigators reported that renal cortical defects were more common in groups of patients with VUR and severity of renal cortical defects was associated with $\mathrm{VUR}^{11,31)}$. Kim et al. reported that patients with a renal uptake difference on DMSA renal scan was larger in patients with high-grade VUR. Therefore, it is reasonable to consider performing VCUG selectively when severe abnormal findings in RBUS and/or DMSA renal scans were detected.

Clinical indicators such as male gender and young age were reported as predicting factors of VUR ${ }^{35,36)}$, however, the results were controversial ${ }^{20,37)}$. The patients' age and sex were unrelated to VUR in this study.

Soylu et al. reported that fever of $>38^{\circ} \mathrm{C}$ and CRP $\geq 5 \mathrm{mg} /$ $\mathrm{dL}$ could be useful clinical predictors of VUR and highgrade VUR, and Oostenbrink et al. reported that a prediction based on age, sex, family history, CRP, and ultrasound was useful for evaluating the likelihood of VUR in children with a first $\mathrm{UTI}^{15,36)}$. Our study found no association of the presence and degree of VUR with the severity and duration of fever or with CRP level. There have also been several studies on whether WBC count can predict VUR, but the results were also controversial ${ }^{15,37,38)}$. In this study, we found that WBC count was not associated with high-grade VUR.

This study has some limitations. This study was retrospectively performed at a single hospital. Interpretation of the images in RBUS and DMSA scan was relatively subjective.

In conclusion, patients with high-grade VUR had a higher incidence of non-E. coli UTI and higher rate of recurrent UTI, and they showed severe abnormal findings on RBUS and DMSA renal scans compared to patients with low-grade VUR or those without VUR. It is desirable to perform VCUG selectively when there are hydronephrosis, ureter dilatation findings in RBUS, multiple cortical defect or difference of uptake difference of both kidneys in DMSA renal scan.

\section{Conflicts of interest}

No potential conflict of interest relevant to this article was reported.

\section{References}

1. Kliegman RM, Stanton B, St Geme R, Schor NF. Nelson Textbook of Pediatrics, 20th edition, Philadelphia: Elsevier, 2016;2556-66.

2. Peters CA, Skoog SJ, Arant Jr BS, Copp HL, Elder JS, Hudson RG, et al. Summary of the AUA guideline on management of primary vesicoureteral reflux in children. J Urol 2010;184:1134-44.

3. Rushton HG. Urinary tract infections in children. Epidemiology, evaluation, and management. Pediatr Clin North Am 1997;44: 1133-69.

4. Subcommittee on Urinary Tract Infection, Steering Committee on Quality Improvement and Management. Urinary tract infection: Clinical practice guideline for the diagnosis and management of the initial UTI in febrile infants and children 2 to 24 months. Pediatrics 2011;128;595-610.

5. Garin EH, Olavarria F, Garcia Nieto V, Valenciano B, Campos A, Young L. Clinical significance of primary vesicoureteral reflux and urinary antibiotic prophylaxis after acute pyelonephritis: a multicenter, randomized, controlled study. Pediatrics 2006;117 (3):626-32.

6. Montini G, Rigon L, Zucchetta P, Fregonese F, Toffolo A, Gobber $D$ et al. Prophylaxis after first febrile urinary tract infection in children? A multicenter, randomized, controlled, noninferiority trial. Pediatrics 2008;122(5):1064-71

7. Estrada Jr CR, Passerotti CC, Graham DA, Peters CA, Bauer SB, Diamond DA, et al. Nomograms for predicting annual resolution rate of primary vesico-ureteral reflux: results from 2,462 children. J Urol 2009;182:1535-41.

8. Elder JS, Peters CA, Arant BS Jr, Ewalt DH, Hawtrey CE, Hurwitz RS, et al. Pediatric Vesicoureteral Reflux Guidelines Panel summary report on the management of primary vesicoureteral reflux in children. J Urol 1997;157:1846.

9. National Institute for Health and Care Excellence. Urinary tract infection in under 16s: diagnosis and management. Clinical guidelines 54. August 2007;1-36

10. Lee SJ. Guidelines for childhood urinary tract infection. Korean J Pediatr 2009:52:976-83.

11. Shaikh N, Ewing AL, Bhatnagar S, Hoberman A. Risk of renal scarring in children with a first urinary tract infection: a systematic review. Pediatrics 2010;126(6):1084-91.

12. Sjöström S, Sillén U, Jodal U, Sameby L, Sixt R, Stokland E. Predictive factors for resolution of congenital high grade vesicoureteral reflux in infants: results of univariate and multivariate analyses. J Urol 2010;183:1177-84. 
13. Arant BS Jr. Vesicoureteral reflux and renal injury. Am J Kidney Dis 1991;17:491-511.

14. Park YS. Renal scar formation after urinary tract infection in children. Korean J Pediatr 2012;55(10):367-70.

15. Soylu A, Kasap B, Demir K, Türkmen M, Kavukçu S. Predictive value of clinical and laboratory variables for vesicoureteral reflux in children. Pediatr Nephrol 2007;22:844-8.

16. Foresman WH, Hulbert WC Jr, Rabinowitz R. Does urinary tract ultra-sonography at hospitalization for acute pyelonephritis predict vesicoure-teral reflux? J Urol 2001;165:2232-4.

17. Mahant S, Friedman J, MacArthur C. Renal ultrasound findings and vesico-ureteral reflux in children hospitalized with urinary tract infection. Arch Dis Child 2002;86:419-20.

18. Choi MJ, Park SJ, Shin JI, Kim KH. Ultrasonographic findings in children with vesicoureteral reflux. J Korean Soc Pediatr Nephrol 2012;16:32-37

19. Weinberg B, Yeung N. Sonographic sign of intermittent dilatation of the renal collecting system in 10 patients with vesicoureteral reflux. J Clin Ultrasound 1998;26(2):65-8.

20. Smellie JM, Normand ICS, Katz G. Children with urinary infection: A comparison of those with and those without vesicoureteric reflux. Kidney International 1981;10:717-722.

21. Ismaili K, Avni FE, Piepsz A, Collier F, Schulman C, Hall M. Vesicoureteric Reflux in Children. EAU-EBU Update series 2006;4;129140.

22. Jang SG, Kong DH, Lee SD. Febrile urinary tract infection in infants: Comparative analysis between primary and recurrent Infection. Korean J UTII 2011;6:186-91.

23. Zorc JJ, Levine DA, Platt SL, Dayan PS, Macias CG, Krief W, et al. Clinical and demographic factors associated with urinary tract infection in young febrile infants. Pediatrics 2005;116;644-8.

24. Sharifian M, Karimi A, Tabatabaei SR, Anvaripour N. Microbial sensitivity pattern in urinary tract infections in children: A single center experience of 1,177 urine cultures. Jpn J Infect Dis 2006; 59(6):380-2.

25. Noor Shafina MN, Nor Azizah A, Mohammad AR, Faisal MF, Mohamad Ikh-san S, Hafizah Z, et al. Bacterial pathogens and antibiotic resistance patterns inchildren with urinary tract infection in a Malaysian tertiary hospital. Med J Malaysia 2015;70(3):153-7.

26. Piljic D, Piljic D, Ahmetagic S, Ljuca F, Porobic Jahic H. Clinical and laboratory characteristics of acute community-acquired urinary tract infections in adult hospitalised patients. Bosn J Basic Med Sci 2010;10(1):49-53.

27. Pauchard JY, Chehade H, Kies CZ, Girardin E, Cachat F, Gehri M. Avoidance of voiding cystourethrography in infants younger than 3 months with Escherichia coli urinary tract infection and normal renal ultrasound. Arch Dis Child 2017;102(9):804-8.

28. Friedman S, Reif S, Assia A, Levy I. Clinical and laboratory characteristics of non-E coli urinary tract infections. Arch Dis Child 2006;91:845-6.

29. Honkinen O, Lehtonen OP, Ruuskanen O, Huovinen P, Mertsola J. Cohort study of bacterial species causing urinary tract infection and urinary tract abnormalities in children. BMJ 1999;318:770-1.

30. Oh JM, Lee NR, Yim HE, Yoo KW, Hong YS, Lee JW. Clinical significance of hydronephrosis in febrile urinary tract infection. J Korean Soc Pediatr Nephrol 2010;14(1):71-8.

31. Lavocat MP, Granjon D, Allard D, Gay C, Freycon MT, Dubois F. Imaging of pyelonephritis. Pediatr Radiol 1997;27(2):159-65.

32. Fouzas S, Krikelli E, Vassilakos P, Gkentzi D, Papanastasiou DA, Salakos C. DMSA scan for revealing vesicoureteral reflux in young children with urinary tract infection. Pediatrics 2010;126(3):e5139.

33. Sheu JN, Wu KH, Chen SM, Tsai JD, Chao YH, Lue KH. Acute 99mTc DMSA scan predicts dilating vesicoureteral reflux in young children with a first febrile urinary tract infection: A population-based cohort study. Clin Nucl Med 2013;38:163-8.

34. Kim BK, Choi WJ, Yim HE, Yoo KH. Clinical Significance of Uptake Difference on DMSA Scintigraphy in Pediatric Urinary Tract Infection. Child Kidney Dis 2016;20(2):63-8.

35. Haycock GB. A practical approach to evaluating urinary tract infection in children. Pediatr Nephrol 1991;5(4):401-2

36. Oostenbrink R, van der Heijden AJ, Moons KGM, Moll HA. Prediction of vesico-ureteric reflux in childhood urinary tract infection: a multivariate approach. Acta Paediatr 2000;89:806-10.

37. Yang EM, Kim SJ, Kim CJ, Woo YJ. Clinical Usefulness of Ultrasonography and 99mTechnetium Dimercaptosuccinic Acid Scan for Predicting the Vesicoureteral Reflux in Children with Urinary Tract Infection. Chonnam Med J 2010;46(1):49-55.

38. Jung JW, Woo MK, Koo JW. Factors Related to the Resolution of Primary Vesicoureteral Reflux. Child Kidney Dis 2009;13(1):40-8. 